\section{Novel immunotherapies in multiple myeloma - chances and challenges}

\author{
Leo Rasche, ${ }^{1,2}$ Ralph Wäsch, ${ }^{3}$ Markus Munder, ${ }^{4,5}$ Hartmut Goldschmidt ${ }^{6,7}$ and \\ Marc S. Raab ${ }^{6,8}$
}

${ }^{1}$ Department of Internal Medicine II, University Hospital of Würzburg, Würzburg; ${ }^{2}$ Mildred Scheel Early Career Center, University Hospital of Würzburg, Würzburg; ${ }^{3}$ Department of Internal Medicine I, University Medical Center, Faculty of Medicine, University of Freiburg, Freiburg; ${ }^{4}$ Third Department of Medicine, University Medical Center of the Johannes Gutenberg University Mainz, Mainz, Germany; ${ }^{5}$ Research Center for Immunotherapy, University Medical Center of the Johannes Gutenberg University Mainz, Mainz; ${ }^{6}$ Department of Internal Medicine V, University Hospital of Heidelberg, Heidelberg; ${ }^{7}$ National Center of Tumor Diseases (NCT), Heidelberg and ${ }^{8} \mathrm{CCU}$ Molecular Hematology/Oncology, German Cancer Research Center (DKFZ), Heidelberg, Germany

\section{ABSTRACT}

$\tau$ $n$ this review article, we summarize the latest data on antibody-drug conjugates, bispecific T-cell-engaging antibodies, and chimeric antigen receptor $\mathrm{T}$ cells in the treatment of multiple myeloma. We discuss the pivotal questions to be addressed as these new immunotherapies become standard agents in the management of multiple myeloma. We also focus on the selection of patients for these therapies and speculate as to how best to individualize treatment approaches. We see these novel immunotherapies as representing a paradigm shift. However, despite the promising preliminary data, many open issues remain to be evaluated in future trials.

\section{Introduction}

Novel immunotherapeutic approaches are seen as the next generation of gamechanging treatments in multiple myeloma (MM). It is a challenge to provide a full overview of novel immunotherapies in this fast-moving field. In the first part of this article, we provide a summary of current clinical data, which have either been published in peer-reviewed journals or been presented at international conferences, including the 2020 American Society of Clinical Oncology, European Hematology Association, and American Society of Hematology (ASH) meetings. In the second part, we discuss these new reports in the context of current treatment paradigms in MM. Given the plethora of immunological approaches in MM, we focus here on the three most advanced classes of novel immunotherapies, antibody-drug conjugates (ADC), bispecific antibodies or T-cell-engaging antibodies (TCE), and chimeric antigen receptor (CAR) $\mathrm{T}$ cells, targeting the antigens described below.

\section{Antigens}

\section{Signaling lymphocytic activation molecule family member 7 (SLAMF7)}

SLAMF7 (or CS1) is expressed on a variety of lymphocytes, including subsets of $B$ and $T$ cells, natural killer cells and plasma cells. SLAMF7 is the target of the monoclonal antibody elotuzumab. The development of CAR T cells directed against SLAMF7 may be more challenging because of this antigen's expression on T-cell subsets which may lead to fratricide. ${ }^{1}$

\section{Cluster of differentiation 38 (CD38)}

CD38 is expressed on plasma cells and is the target of monoclonal antibodies such as daratumumab and isatuximab. It is also expressed on several other lymphoid and myeloid cells, including hematopoietic precursors, raising concerns about on-target, off-tumor toxicity. The levels of expression of CD38 may also decline during the course of the disease or under the selective pressure of CD38targeted treatment. This problem may be overcome by agents inducing selective
Ferrata Storti Foundation
Haematologica 2021
Volume 106(10):2555-2565

\section{Correspondence: \\ MARC S. RAAB \\ Marc.Raab@med.uni-heidelberg.de}

Received: February 12, 2021.

Accepted: April 29, 2021.

Pre-published: July 1, 2021.

https://doi.org/10.3324/haematol.2020.266858

(C)2021 Ferrata Storti Foundation

Material published in Haematologica is covered by copyright. All rights are reserved to the Ferrata Storti Foundation. Use of published material is allowed under the following terms and conditions:

https://creativecommons.org/licenses/by-nc/4.0/legalcode. Copies of published material are allowed for personal or internal use. Sharing published material for non-commercial purposes is subject to the following conditions:

https://creativecommons.org/licenses/by-nc/4.0/legalcode, sect. 3. Reproducing and sharing published material for commercial purposes is not allowed without permission in writing from the publisher. 
upregulation of CD38, such as all-trans retinoic acid, histone deacetylase inhibitors or ruxolitinib..$^{2 \cdot 4}$

\section{B-cell maturation antigen (BCMA)}

BCMA is preferentially expressed on mature B cells including plasma cells. It is important for B-cell development and critical for proliferation and survival. BCMA is a cell surface receptor of the tumor necrosis factor receptor superfamily and binds to B-cell activating factor (BAFF) and a proliferation-inducing ligand (APRIL). BCMA expression can vary due to cleavage by $\gamma$-secretase leading to shedding from the cell surface.

\section{Transmembrane activator, calcium modulator, and cyclophilin ligand (TACI)}

TACI is another member of the tumor necrosis factor receptor superfamily expressed on B-cell subsets and plasma cells.

\section{Cluster of differentiation 19 (CD19)}

CD19 is widely expressed on B cells but considerably less on plasma cells. It has been postulated that it may be expressed on "myeloma stem cells". Recent analysis by super-resolution microscopy revealed a broader low-level expression on a fraction of myeloma cells $(10-80 \%) .^{5}$

\section{G protein-coupled receptor class C group 5 member D (GPRC5D)}

GPRC5D is an orphan receptor ubiquitously expressed on healthy and malignant plasma cells but not on normal tissues except the immune-privileged tissue of hair follicles. High GPRC5D expression on MM cells was associated with adverse prognosis in the CoMMpass dataset. ${ }^{6}$

\section{Fc receptor-homolog 5 (FcRH5)}

FcRH5, also known as FcRL5, IRTA2, and CD307, is a $120 \mathrm{kDa}$ protein with sequence homology to classical Fc receptors. The type 1 transmembrane FCRL family proteins contain from three to nine immunoglobulin-like domains. They are differentially expressed within the Bcell lineage and can either promote or inhibit B-cell proliferation and activation. FcRH5 is expressed on MM cells and plasma cells and, to a lesser extent, on normal B cells.?

\section{Antibody-drug conjugates}

$\mathrm{ADC}$ are monoclonal antibodies conjugated via a linker to a cytotoxic moiety. ${ }^{8}$ After binding to the respective target protein on the myeloma cell, the ADC is internalized and the cytotoxic drug released intracellularly; they can be thought of as targeted chemotherapeutic agents. ADC differ with respect to the target protein, the linker or the cytotoxic payload. ${ }^{8}$ In the following section, some key ADC, the study results and our perspectives are highlighted. This selection is far from exhaustive and the interested reader is referred to more detailed reviews regarding this topic.,

\section{Belantamab mafodotin}

By far the most clinically advanced ADC is belantamab mafodotin, a humanized IgG1 anti-BCMA monoclonal antibody that is conjugated, via a non-cleavable linker, to the microtubule inhibitor, monomethyl auristatin $\mathrm{F}$ (MMAF). MMAF blocks the myeloma cell cycle at the
G2/M phase leading to apoptosis. Afucosylation of the ADC Fc portion enhances the affinity to Fc receptors of innate immune cells, which increases immune-mediated recognition and elimination. Therefore, belantamab mafodotin can also be considered as immunotherapy. ${ }^{10}$ (Figure 1)

Two dose levels $(2.5 \mathrm{mg} / \mathrm{kg}$ or $3.4 \mathrm{mg} / \mathrm{kg}$, intravenously every 3 weeks) of belantamab mafodotin were tested in the pivotal randomized phase II DREAMM-2 study in heavily pretreated (6-7 prior lines of therapy) patients with relapsed and/or refractory MM (RRMM): The efficacy of the ADC was comparable at the two dose levels, with the overall response rate (ORR) being $31 \%$ versus $35 \%$ and the progression-free survival (PFS) being 2.8 months versus 3.9 months in the $2.5 \mathrm{mg} / \mathrm{kg}$ and $3.4 \mathrm{mg} / \mathrm{kg}$ cohorts, respectively. Duration of response was 11.0 and 6.2 months, while the overall survival was 14.9 and 14.0 months, respectively (Table 1$).^{11}$

The MMAF component of belantamab mafodotin is responsible for clinically significant ocular toxicity: microcyst-like epithelial changes of the cornea. ${ }^{12}$ Clinically, patients experience blurred vision, decreased visual acuity and dry eyes. In DREAMM-2, keratopathy was noted in $70-75 \%$ of patients and was grade $\geq 3$ in $27 \%$ (with the 2.5 $\mathrm{mg} / \mathrm{kg}$ dose) and $21 \%$ (with the $3.4 \mathrm{mg} / \mathrm{kg}$ dose) of the patients. Keratopathy was the most common adverse event leading to dose reductions and delays as well as to permanent treatment discontinuation. It is therefore mandatory to schedule regular ophthalmological examinations when treating MM patients with this novel ADC.

In summary, the DREAMM-2 study demonstrated that belantamab mafodotin has clinically significant efficacy as a single agent and it was approved (at a dose of $2.5 \mathrm{mg} / \mathrm{kg}$ every 3 weeks) in both the USA and in Europe in 2020 for the treatment of RRMM patients after four lines of therapy (including a proteasome inhibitor, immunomodulatory drug and an anti-CD38 monoclonal antibody).

Based on the DREAMM-2 study results, belantamab mafodotin is currently being assessed in trials at earlier lines of treatment and with different combination partners: ${ }^{9}$ immuno-oncological antibodies (DREAMM- $4,{ }^{13}$ DREAMM-5) or established MM therapeutics lenalidomide + dexamethasone (DREAMM-6), ${ }^{14}$ pomalidomide + dexamethasone ${ }^{15}$ bortezomib + dexamethasone (DREAMM-6, ${ }^{14}$ DREAMM-7) and bortezomib + lenalidomide + dexamethasone (DREAMM-9).

Table 1 summarizes key studies of this program for which efficacy and toxicity data are already available. Further details and summaries of all ongoing studies with belantamab mafodotin are provided in comprehensive recent reviews. $8,9,16$

\section{MEDI2228}

MEDI2228 is another ADC targeting BCMA. The cytotoxic moiety is tesirine, a DNA crosslinking pyrrolobenzodiazepine dimer attached to the antibody via a protease-cleavable linker. This toxin induces DNA crosslinking and the DNA damage response. ${ }^{17}$ The ADC was designed to specifically target the membrane-bound BCMA protein, so that its activity is not affected by the levels of soluble BCMA.

The results of the phase I, first-in-human, dose escalation and expansion study (NCT03489525) involving 82 heavily pretreated RRMM patients were presented at the 2020 ASH annual meeting. ${ }^{18}$ The maximum tolerated 
dose was found to be $0.14 \mathrm{mg} / \mathrm{kg}$ every 3 weeks and, within the cohort given this dose (41 patients), the ORR was $61 \%$ (24\% with a very good partial response and $37 \%$ with a partial response). This efficacy was similar to that observed in the belantamab mafodotin DREAMM-1 trial (Table 1). ${ }^{19}$

However, unexpected ocular toxicity occurred: $54 \%$ of the patients given the maximum tolerated dose developed an as-yet unexplained photophobia. This toxicity, which led to treatment discontinuation in a large subgroup of patients, appears to be unrelated to the belantamab mafodotin-induced keratopathy. Other MEDI2228-induced toxicities were thrombocytopenia $(32 \%)$, rash $(29 \%)$ and pleural effusions $(20 \%){ }^{18}$

\section{AMG 224}

The ADC AMG 224 is a BCMA-directed IgG1 monoclonal antibody coupled to the tubulin inhibitor mertansine (also called DM1). The results of the first phase I dose expansion and escalation study (NCT02561962) have recently been reported..$^{20}$ In all 40 patients, the ORR was $23 \%$, including two patients with a stringent complete response and two with a very good partial response. The ADC was tolerated up to the defined maximum tolerated dose of $190 \mathrm{mg}$ intravenously every 3 weeks. Hematologic toxicity, mainly thrombocytopenia $(40 \% \geq$ grade 3), was the most common adverse event. No dose reductions, delays or $\mathrm{ADC}$ discontinuation were necessary due to ophthalmological adverse events (any grade: $30 \%$ ). Ocular toxicity seems to be less common with this
ADC than with the MMAF-conjugated belantamab mafodotin (Table 1). ${ }^{20}$

The following $\mathrm{ADC}$ are in (pre-)clinical development, but no relevant clinical efficacy data have been reported so far.

\section{CC99712}

The ADC CC99712, which is currently being evaluated in a phase I study (NCT04036461), also targets BCMA. Its toxic payload is the tubulin inhibitor monomethyl auristatin E. ${ }^{9}$

\section{TAK-169 and TAK-573}

TAK-169 and TAK-573 are two CD38-directed ADC in early clinical development. TAK-169 is linked to a deimmunized Shiga-like toxin A subunit. Preclinical studies demonstrated highly effective lysis of primary MM cells in vitro. ${ }^{21}$ No clinical data regarding the ongoing phase I study (NCT04017130) are yet available. TAK-573 targets a CD38 epitope for which cross-reactivity with the currently approved anti-CD38 monoclonal antibodies, daratumumab and isatuximab, is not anticipated. It is linked to two attenuated interferon $\alpha 2 b$ molecules. A first-inhuman, dose-escalation, phase I trial (NCT 3215030), which is also assessing different treatment schedules, is currently recruiting patients. Early data focused on pharmacokinetic and immunological parameters have revealed limited clinical responses in MM patients across all four treatment cohorts. ${ }^{22}$

Table 1. Clinical trial results with antibody-drug conjugates.

\begin{tabular}{|c|c|c|c|c|c|c|c|c|c|c|c|}
\hline ADC name & Target & Toxin & Trial regimen & $\begin{array}{l}\text { Trial name } \\
\text { registration n. }\end{array}$ & $\begin{array}{l}\text { Patients } \\
\text { n (dose) }\end{array}$ & $\begin{array}{l}\text { Prior lines } \\
\text { of TX (n) }\end{array}$ & $\begin{array}{l}\text { ORR } \\
(\%)\end{array}$ & $\begin{array}{c}\geq \operatorname{VGPR} \\
(\%)\end{array}$ & $\begin{array}{c}\text { PFS } \\
\text { (months) }\end{array}$ & $\begin{array}{l}\text { Toxicity } \\
\text { (sclected) }\end{array}$ & Ref. \\
\hline \multirow[t]{6}{*}{$\begin{array}{l}\text { Belantamab } \\
\text { mafodotin }\end{array}$} & \multirow[t]{6}{*}{ BCMA } & \multirow[t]{6}{*}{$\begin{array}{c}\text { Monomethyl } \\
\text { auristatin F } \\
\text { (MMAF) }\end{array}$} & $\begin{array}{l}\text { Monotherapy } \\
\text { Dose escalation } \\
\text { and expansion }\end{array}$ & $\begin{array}{c}\text { DREAMM-1 } \\
\text { (NCT02064387) }\end{array}$ & $\begin{array}{c}35 \\
(3.4 \mathrm{mg} / \mathrm{kg})\end{array}$ & $\geq 5(57 \%)$ & 60 & 54 & 12 & $\begin{array}{l}\text { Keratopathy: } \\
\text { any grade: } 69 \% \\
\text { Thrombocytopenia } \\
\text { any grade: } 63 \%\end{array}$ & 19 \\
\hline & & & $\begin{array}{l}\text { Monotherapy } \\
2 \text { doses: } \\
2.5 \mathrm{mg} / \mathrm{kg} v \mathrm{~s} \text {. } \\
3.4 \mathrm{mg} / \mathrm{kg}\end{array}$ & $\begin{array}{c}\text { DREAMM-2 } \\
\text { (NCT03525678) }\end{array}$ & $\begin{array}{c}97 \\
(2.5 \mathrm{mg} / \mathrm{kg}) \\
99 \\
(3.4 \mathrm{mg} / \mathrm{kg})\end{array}$ & 7 & 31 & 22 & 2.8 & $\begin{array}{c}\text { Keratopathy } \\
\text { any grade: } 70 \% \\
\geq \text { grade } 3: 27 \% \\
\text { Keratopathy } \\
\text { any grade: } 75 \% \\
\geq \text { grade } 3: 21 \%\end{array}$ & 11 \\
\hline & & & $\begin{array}{c}2.5 \mathrm{mg} / \mathrm{kg} \text { vs. } \\
3.4 \mathrm{mg} / \mathrm{kg}\end{array}$ & $\begin{array}{c}\text { DREAMM-4 } \\
\text { (NCT03848845) }\end{array}$ & $\begin{array}{c}6 \\
(2.5 \mathrm{mg} / \mathrm{kg})\end{array}$ & 7 & 67 & 50 & NR & $\begin{array}{c}\text { Keratopathy } \\
\text { any grade: } 83 \%\end{array}$ & 13 \\
\hline & & & + pembrolizumab & & $\begin{array}{c}7 \\
(3.4 \mathrm{mg} / \mathrm{kg})\end{array}$ & 5 & 43 & 0 & & any grade: $57 \%$ & \\
\hline & & & $\begin{array}{l}2.5 \text { vs. } 3.4 \mathrm{mg} / \mathrm{kg} \\
\text { Irm B:+ bortezomib } \\
\text { dexamethasone }\end{array}$ & $\begin{array}{c}\text { DREAMM-6 } \\
\text { / (NCT03544281) }\end{array}$ & $\begin{array}{c}18 \\
(2.5 \mathrm{mg} / \mathrm{kg})\end{array}$ & 3 & 78 & 50 & NR & $\begin{array}{c}\text { Keratopathy } \\
\text { any grade: } 100 \% \\
\text { grade } 3-4: 56 \%\end{array}$ & 14 \\
\hline & & & $\begin{array}{l}\text { + pomalidomide / } \\
\text { dexamethasone }\end{array}$ & $\begin{array}{c}\text { Algonquin } \\
\text { (NCT03715478) }\end{array}$ & $\begin{array}{c}37 \\
\text { (all cohorts) }\end{array}$ & 3 & 88 & 68 & NR & $\begin{array}{c}\text { Keratopathy } \\
\text { any grade: } 76 \% \\
\geq \text { grade } 3: 51 \%\end{array}$ & 15 \\
\hline AMG 224 & BCMA & $\begin{array}{l}\text { Mertansine } \\
\text { (DM1) }\end{array}$ & $\begin{array}{l}\text { Monotherapy } \\
\text { Dose escalation } \\
\text { and expansion }\end{array}$ & (NCT02561962) & $\begin{array}{c}40 \\
\text { (total) }\end{array}$ & 7 & 23 & 10 & NR & 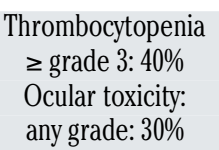 & 20 \\
\hline MEDI2228 & BCMA & Tesirine & $\begin{array}{l}\text { Monotherapy } \\
\text { Dose escalation } \\
\text { and expansion }\end{array}$ & (NCT03489525) & $\begin{array}{l}41 \text { (at MTD } \\
0,14 \mathrm{mg} / \mathrm{kg} \text { ) } \\
\text { (total: } 82 \text { ) }\end{array}$ & $2-11$ & 61 & 24 & NR & Photophobia: 54\% & 18 \\
\hline
\end{tabular}




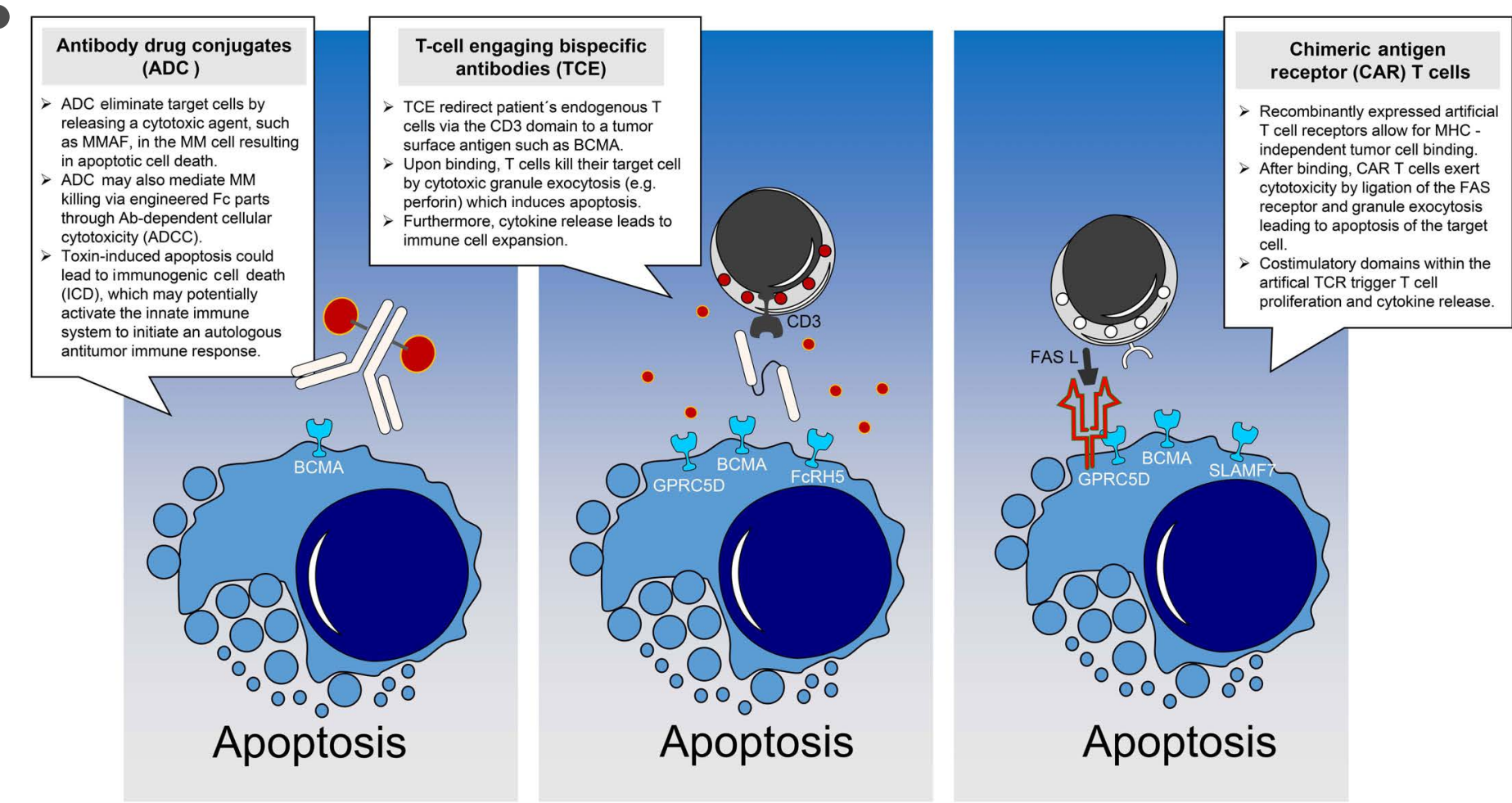

Figure 1. Mode of action illustrated for antibody-drug conjugates, T-cell-engaging antibodies and chimeric antigen receptor T cells. MMAF: monomethyl auristatin F; MM: multiple myeloma; BCMA: B-cell maturation antigen; TCR: T-cell receptor.

\section{FOR-46}

The MMAF-coupled ADC FOR-46, currently undergoing evaluation in a phase I, dose-escalation study (NCT03650491), is directed against the complement regulatory protein $\mathrm{CD} 46$. This ADC targets a tumor-specific epitope of CD46 and efficiently induces macropinocytosis. ${ }^{23}$

\section{HDP-101}

The cytotoxic potential of the ADC HDP-101 is based on a synthetic version of the Amanita phalloides toxin amanitin, a specific inhibitor of RNA polymerase II. ${ }^{24}$ This inhibition of gene transcription and protein synthesis is cell cycleindependent, an important property given that in many cases a large fraction of $\mathrm{MM}$ cells are not proliferating. This rare property may be a clinically important characteristic of HDP-101. Due to its chromosomal location, RNA polymerase II is frequently co-deleted with TP53 in $\operatorname{del}(17 \mathrm{p})$. $\mathrm{MM}$ cells with this high-risk feature are therefore likely to be highly sensitive to HDP-101. Promising preclinical safety and activity data have been reported ${ }^{25}$ and a first-inhuman, phase I, dose escalation and expansion study for RRMM patients is planned for $2021 .{ }^{26}$

\section{Bispecific antibodies}

Bispecific TCE represent another approach to treating $\mathrm{MM}$, utilizing the high cytolytic activity of $\mathrm{T}$ cells. While one arm binds to a plasma cell or B-cell lineage associated antigen, a second arm recruits $\mathrm{T}$ cells via the CD3 domain, thereby bringing $T$ cells in close proximity to $\mathrm{MM}$ cells, ultimately leading to granzyme and perforin exocytosis and apoptosis of the target cell (Figure 1).

\section{AMG 420}

Proof-of-principle of the validity of this strategy was recently provided by a study on AMG 420, a bispecific $T$ cell-engager $\left(\mathrm{BiTE}^{\oplus}\right)$ targeting $\mathrm{BCMA} .{ }^{27}$ In a dose-escalating phase I study in RRMM, ${ }^{27}$ the ORR was $70 \%$ at a dose of $400 \mathrm{mg} /$ day and some patients responded for more than 1 year. In a single-center study, the median PFS was 23.5 months for responders $(\mathrm{n}=10) .{ }^{28}$ Like the CD19xCD3 BiTE blinatumomab, AMG 420 has a short half-life with rapid elimination from the circulation. Continuous infusion over weeks was therefore necessary, causing substantial inconvenience to patients. In light of the multiple other TCE variants with longer half-lives under clinical investigation, the manufacturer did not pursue further development of AMG 420. Numerous abstracts on TCE were presented at the ASH annual meeting in 2020, and initial clinical data on at least seven new TCE were reported (Table 2).

\section{Teclistamab}

Teclistamab (JNJ-64007957) is a humanized bispecific IgG4 antibody that binds to BCMA on target cells and CD3 on $T$ cells (BCMA $x$ CD3). Currently being evaluated in an ongoing phase I study, teclistamab is available in both intravenous and subcutaneous formulations, and is administered on a weekly schedule. Updated results from 149 patients, presented at ASH in 2020, showed a favorable safety profile and promising efficacy. ${ }^{29}$ Although cytokine release syndrome (CRS) was seen in more than half of the patients $(55 \%$ in the intravenous group, and $64 \%$ in the subcutaneous group), no grade 3 CRS was recorded, and no dose-limiting toxicity was reported at the recommended phase II dose of $1500 \mu \mathrm{g} / \mathrm{kg}$ subcutaneously. The ORR was $73 \%$, with $55 \%$ of the patients achieving a very good partial response or better at the recommended phase II 
Table 2. Clinical trial results with T-cell-engaging antibodies.

\begin{tabular}{|c|c|c|c|c|c|c|c|}
\hline $\begin{array}{l}\text { Study product } \\
\text { (Registration n.) }\end{array}$ & $\begin{array}{c}\text { Study } \\
\text { population }\end{array}$ & Schedule & CRS profile & Neurotoxicity & Response & Last cohorts (n) & Ref. \\
\hline \multicolumn{8}{|c|}{ B-cell maturation antigen (BCMA) } \\
\hline $\begin{array}{l}\text { Teclistamab } \\
\text { (NCT03145181) }\end{array}$ & $\begin{array}{l}\text { Dara/IMID/PI } \\
\quad+\text { EMD }\end{array}$ & $\begin{array}{c}\text { i.v. } n=84 \\
\text { s.c. } n=44 \\
\text { QW }\end{array}$ & $\begin{array}{l}\text { s.c. } 50 \% \text { i.v. } 53 \% \\
\text { Grade 3/4: } 0 \%\end{array}$ & $3 \%$ & $\begin{array}{c}\text { ORR: } 25 \% \\
\text { CR/sCR: } 9 / 120\end{array}$ & $\begin{array}{c}\text { ORR: } 63.8 \%(30 / 47) \\
\text { CR/sCR: } 19.5 \%(9 / 47)\end{array}$ & 29 \\
\hline $\begin{array}{l}\text { REGN } 5458 \\
\text { (NCT03761108) }\end{array}$ & $\begin{array}{c}\text { Dara/IMID/PI } \\
+ \text { EMD } \\
\text { asecretory included }\end{array}$ & $\begin{array}{c}\text { i.v. } \mathrm{n}=45 \\
\mathrm{QW}\end{array}$ & $\begin{array}{c}\text { 88.2\% } \\
\text { Grade 3/4: 0\% }\end{array}$ & $\mathrm{NA}$ & $\begin{array}{c}\text { ORR: } 35,8 \% \\
\text { CR/sCR: } 6 / 45\end{array}$ & $\begin{array}{l}\text { ORR: } 60 \% \\
\text { NR }\end{array}$ & 30 \\
\hline $\begin{array}{l}\text { AMG } 701 \\
\text { NCT03287908 }\end{array}$ & $\begin{array}{l}\text { Dara/IMID/PI } \\
\quad \text { - EMD }\end{array}$ & $\begin{array}{c}\text { i.v.; } \\
\text { Q2-Q2W }\end{array}$ & $\begin{array}{c}61 \% \\
\text { Grade 3/4: } 8 \%\end{array}$ & $\mathrm{NA}$ & $\begin{array}{c}\text { ORR: } 23,2 \% \\
\text { CR/sCR: } 5 / 69\end{array}$ & $\begin{array}{c}\text { ORR: } 29,6 \%(8 / 27) \\
\text { CR/CRs: } 11.1 \%(3 / 27)\end{array}$ & 33 \\
\hline $\begin{array}{l}\text { TNB-38384 } \\
\text { (NCT03933735) }\end{array}$ & $\begin{array}{l}\text { Dara/IMID/PI } \\
\quad+\text { EMD }\end{array}$ & $\begin{array}{c}\text { i.v. } \mathrm{n}=38 \\
\mathrm{Q} 3 \mathrm{~W}\end{array}$ & $\begin{array}{c}21 \% \\
\text { Grade 3/4: } 0 \% \\
\end{array}$ & $\mathrm{NA}$ & $\begin{array}{c}\text { ORR: } 37 \% \\
\text { CR/sCR: } 3 / 38 \\
\end{array}$ & $\begin{array}{c}\text { ORR: } 52 \%(12 / 23) \\
\text { CR/CRs: } 13 \%(3 / 23)\end{array}$ & 32 \\
\hline PF-3135 & & $\begin{array}{c}\mathrm{sc}, \\
\mathrm{QW} / \mathrm{Q} 2 \mathrm{~W}\end{array}$ & $\begin{array}{c}90 \% \\
\text { Grade 3/4: } 0 \%\end{array}$ & $20 \%$ & & $80 \%$ & 34 \\
\hline $\begin{array}{l}\text { CC-932695 } \\
\text { (NCT03486067) }\end{array}$ & $\begin{array}{l}\text { Dara/IMID/PI } \\
\quad+\text { EMD }\end{array}$ & $\begin{array}{c}\text { i.v. } \mathrm{n}=30 \\
\mathrm{QW}\end{array}$ & $\begin{array}{c}77 \% \\
\text { Grade 3/4: 9\% } \\
\text { Grade 5: } 1 \text { death }\end{array}$ & NA & $\begin{array}{l}\text { ORR: } 40 \% \\
\text { CRsCR: } 5 / 30\end{array}$ & $\begin{array}{c}\text { ORR: } 88,8 \%(8 / 9) \\
\text { CR/CRs: } 44,4 \%(4 / 9)\end{array}$ & 36 \\
\hline $\begin{array}{l}\text { G-protein couple } \\
\text { Talquetatamab } \\
\text { (NCT03399799) }\end{array}$ & or family $\mathrm{C}$ group 5 & $\begin{array}{l}\text { er } D(G P R \\
\text { i.v. } n=102 \\
\text { s.c. } n=35\end{array}$ & $\begin{array}{l}\text { i.v.+ s.c.: } 47 \% \\
\text { i.v. Grade 3/4: } 8 \% \\
\text { s.c. Grade } 3 / 4: 0\end{array}$ & $\begin{array}{c}\text { 7/137 } \\
\text { G1/2: } 4 \text { G3: } 3 \\
\text { 6/7 with CRS }\end{array}$ & & $\begin{array}{l}\text { i.v.: ORR: 14/18 } \\
\text { s.c.: ORR: 8/12 }\end{array}$ & 39 \\
\hline $\begin{array}{l}\text { Fc receptor-hom } \\
\text { Cevostamab (prev } \\
\text { (NCT03275103) }\end{array}$ & $\begin{array}{l}\text { (cRH5) } \\
\left.350 \mathrm{~A}^{2}\right)\end{array}$ & $\begin{array}{c}\text { i.v. } \mathrm{n}=51 \\
\mathrm{QW}\end{array}$ & $\begin{array}{c}\quad 74.5 \% \\
\text { Grade 3/4: } 2 \% \\
\end{array}$ & $5 \%$ & & & 40 \\
\hline
\end{tabular}

TCE: T-cell-engager; CRS: cytokine release syndrome; Dara: daratumumab; IMID: immunomodulatory drug; PI: proteasome inhibitor; EMD: extramedullary disease; i.v: intravenous; s.c.: subcutaneous; ORR: overall response rate; CR: complete response, sCR: stringent complete response; QW: once weekly; Q2W: every 2 weeks; Q3W: every 3 weeks; NA: not applicable; NR: not reported; G: grade.

dose, including patients with triple-class and penta-drug RRMM. However, follow-up is limited (median 3.9 months) and it remains to be seen if these responses are durable and if patients with highly proliferative disease or extramedullary involvement have a similar benefit. A phase II study has been initiated.

\section{REGN5458}

Another TCE that binds BCMA and CD3, REGN5458, was evaluated in 45 patients in a dose-escalation, phase I study. ${ }^{30}$ This TCE was administered intravenously on a weekly schedule followed by a maintenance phase in which it was administered every 2 weeks. CRS occurred in $38 \%$ of patients, but there were no episodes of grade $\geq 3$ CRS. The ORR increased in a dose-dependent manner and was $62.5 \%$ (5/8 patients) at the highest dose level used. Responses were deep and $95 \%$ of responders achieved a very good partial response or better. The median duration of follow-up was 2.6 months. The phase II part of the study is currently enrolling patients.

\section{TNB383B}

TNB383B is a BCMA x CD3 fully human IgG4 antibody with improved binding to cell surface BCMA and a half-life of 2-3 weeks. ${ }^{31}$ It is administered once every 3 weeks and is given intravenously. Decreased affinity to CD3 may be responsible for the lower rate of CRS associated with this product. The all-grade CRS rate was $45 \%$ in the phase I dose escalation study which enrolled 58 patients. ${ }^{32}$ The ORR was $80 \%$ in the highest dose group $(\mathrm{n}=15)$. Two patients died from COVID-19 infection.

\section{AMG 701}

AMG 701 is a derivative of AMG 420 with a modified
$\mathrm{BiTE}^{\circledR}$ structure resulting in an extended half-life of around 112 hours, making it suitable for once weekly dosing. A total of 82 patients were treated in the doseescalation phase I study. The ORR was $26 \%$ and $83 \%$ in the entire study population and in the most recent evaluable cohort, respectively. ${ }^{33}$ Extramedullary disease was excluded in subcohorts of this study. AMG 701 was given intravenously on a weekly schedule with a step-up dose during the first cycle to reduce CRS, which was seen in $61 \%$ of patients including $7 \%$ who experienced grade 3 CRS. Exposure to free drug was affected to some extent by the levels of soluble BCMA, suggesting a possible interaction between the TCE and soluble antigens. The recommended phase II dose has yet to be determined.

\section{PF-06863135}

PF-06863135 is a BCMA x CD3 humanized IgG2a antibody being evaluated in a subcutaneous formulation in an ongoing phase I study. At the 2020 ASH meeting, results from the first 18 patients were presented, indicating an ORR of $33 \%$ in the overall population, and $75 \%$ in patients receiving the two highest dose levels. The CRS rate was $61 \%$ with no CRS grade 3 events. ${ }^{34}$

\section{CC-93269}

This asymmetric, two-arm, humanized IgG BCMA x CD3 antibody is also being evaluated in a phase I study. ${ }^{35}$ The initial data from 19 patients, presented at the ASH meeting in 2019, indicated an ORR of around $80 \%$ at effective dose levels, but also CRS in over $80 \%$ of patients including one case that was fatal. ${ }^{36}$ The recommended phase II dose has yet to be determined and follow-up data are awaited.

The specific and consistent expression of BCMA on 
Table 3. Clinical trials with B-cell maturation antigen chimeric antigen receptor T cells.

\begin{tabular}{|c|c|c|c|c|c|c|c|c|c|c|c|c|}
\hline CAR & Construct & Cell dose & Trial & Sponsor & N & ORR & CR & PFS & $\begin{array}{l}\text { Cytopenia } 3 / 4 \\
\text { grade } 3 / 4\end{array}$ & $\begin{array}{c}\text { CRS } \\
\text { grade } 3 / 4\end{array}$ & $\begin{array}{c}\text { ICANS } \\
\text { grade } 3 / 4\end{array}$ & 4 \\
\hline $\begin{array}{l}\text { BCMA/ } \\
\text { CD28 }\end{array}$ & & $9 \times 10^{6}$ cells / kg bw & First-in-humans & $\mathrm{NIH}$ & 16 & $81 \%$ & $13 \%$ & $7.8 \mathrm{mo}$ & prolonged $13 \%$ & $38 \%$ & $6 \%$ & 44,45 \\
\hline $\begin{array}{l}\text { BCMA/ } \\
4-1 \mathrm{BB}\end{array}$ & & $\begin{array}{l}\mathrm{C} 1: 1-5 \times 10^{8} \text { total cells } \\
\mathrm{C} 2: \mathrm{Cy}+1-5 \times 10^{7} \text { total cells } \\
\mathrm{C} 3: \mathrm{Cy}+1-5 \times 10^{8} \text { total cells }\end{array}$ & Phase I & UPenn & 25 & $\begin{array}{c}48 \% \\
\text { C3: } 64 \%\end{array}$ & $8 \%$ & $\begin{array}{l}\text { MDOR } \\
4.2 \mathrm{mo}\end{array}$ & $\begin{array}{l}\text { neutropenia 44\% } \\
\text { thrombopenia 28\% }\end{array}$ & $32 \%$ & $12 \%$ & 37 \\
\hline $\begin{array}{l}\text { BCMA/ } \\
\text { CD28 }\end{array}$ & $\begin{array}{l}\text { Ide-cel } \\
\text { (bb2121) }\end{array}$ & $50-800 \times 10^{6}$ total cells & $\begin{array}{l}\text { CRB-401 } \\
\text { (Phase I) }\end{array}$ & $\begin{array}{l}\text { BMS / } \\
\text { Celgene }\end{array}$ & 60 & $62 \%$ & $39 \%$ & $8.8 \mathrm{mo}$ & $\begin{array}{l}\text { leukopenia } 61 \% \\
\text { neutropenia } 89 \% \\
\text { thrombopenia } 57 \%\end{array}$ & $7 \%$ & $2 \%$ & 46,47 \\
\hline $\begin{array}{l}\text { BCMA/ } \\
\text { CD28 }\end{array}$ & $\begin{array}{l}\text { Ide-cel } \\
\text { (bb2121) }\end{array}$ & $150-450 \times 10^{6}$ total cells & KarMMa & $\begin{array}{l}\text { BMS / } \\
\text { Celgene }\end{array}$ & 128 & $73 \%$ & $33 \%$ & $8.8 \mathrm{mo}$ & $\begin{array}{l}\text { leukopenia } 39 \% \\
\text { neutropenia } 89 \% \\
\text { thrombopenia } 52 \%\end{array}$ & $5 \%$ & $3 \% \quad 4$ & $45,48,49$ \\
\hline $\begin{array}{l}\text { BCMA/ } \\
4-1 \mathrm{BB}\end{array}$ & $\begin{array}{c}\text { Cilta-cel } \\
\text { (LCAR-B38M) }\end{array}$ & med. $0.5 \times 10^{6}$ cells / kg bw & $\begin{array}{l}\text { LEGEND-2 } \\
\text { (Phase I) }\end{array}$ & China & 57 & $88 \%$ & $74 \%$ & $19.9 \mathrm{mo}$ & $\begin{array}{l}\text { leukopenia 30\% } \\
\text { thrombopenia } 23 \%\end{array}$ & $7 \%$ & $0 \%$ & $50-52$ \\
\hline $\begin{array}{l}\text { BCMA/ } \\
4-1 \mathrm{BB}\end{array}$ & $\begin{array}{c}\text { Cilta-cel } \\
\text { (JNJ-4528) }\end{array}$ & med. $0.71 \times 10^{6}$ cells $/ \mathrm{kg}$ bw & $\begin{array}{l}\text { CARTITUDE-1 } \\
\text { (Phase I / II) }\end{array}$ & Janssen & 97 & $97 \%$ & $67 \%$ & $\begin{array}{c}\mathrm{NR} \\
\text { FU } 12.4 \mathrm{mo}\end{array}$ & $\begin{array}{l}\text { leukopenia } 61 \% \\
\text { neutropenia } 95 \% \\
\text { thrombopenia } 69 \%\end{array}$ & $5 \%$ & $2 \%$ & $52-55$ \\
\hline
\end{tabular}

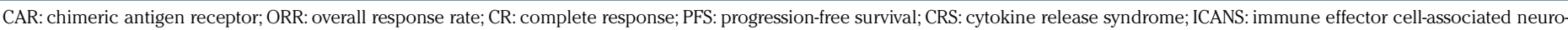

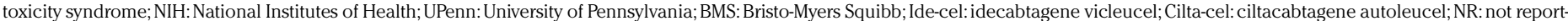
ed; FU: follow-up.

plasma cells makes this antigen an ideal target protein for T-cell-based immunotherapy. However, a number of other cell surface receptors share these characteristics and are being targeted with TCE in ongoing trials. This is of particular interest, as BCMA downregulation ${ }^{37}$ and even irreversible loss ${ }^{38}$ of BCMA expression has been reported following treatment with targeted immunotherapies.

\section{Talquetamab}

Talquetamab is a GPRC5D x CD3 TCE which has been evaluated in a dose-escalation phase I study, ${ }^{39}$ in which it was administered both intravenously and subcutaneously. A total of 175 patients were treated and a dose of 405 $\mu \mathrm{g} / \mathrm{kg}$ was defined as the recommended phase II dose. At this dose, $69 \%(9 / 13)$ of patients responded, including two who had stringent complete responses. Dose-limiting toxicities included increased lipase (grade 4) and maculopapular rash (grade 3 ) in one and two subjects, respectively. Skin-related off-target effects and nail disorders were seen in a significant proportion of patients. CRS occurred in $55 \%$ of the patients but was generally low grade with no grade $\geq 3$ CRS in those administered the product subcutaneously.

\section{Cevostamab}

This FCRH5 x CD3 humanized IgG-based TCE is being evaluated in an ongoing phase I, dose escalation and expansion trial (NCT03275103). FcRH5 is expressed on $\mathrm{MM}$ cells and plasma cells and, to a lesser extent, on normal B cells. ${ }^{7}$ The ORR was $53 \%(18 / 34)$ in patients receiving active doses, and six patients achieved minimal residual disease negativity at a threshold of $10^{5}$. CRS occurred in $76 \%$ of patients with one patient experiencing grade 3 CRS. ${ }^{40}$ The dose escalation and expansion phase is ongoing.

In summary, there is an extensive pipeline of TCE targeting $\mathrm{BCMA}$ and other antigens, with response rates to these products being between $50 \%$ and $80 \%$, including some deep responses in heavily pretreated patients. CRS is common during the first cycle of treatment, but is manageable with step-up dosing schedules and the use of pro- phylaxis. Short intravenous infusions or subcutaneous formulations offer convenient administration in the outpatient setting. Several other TCE are in early clinical development with clinical data yet to be reported.

\section{Chimeric antigen receptor T-cell approaches}

CAR T cells have emerged as a highly promising new therapeutic approach in cancer. The first success was observed with CAR T cells targeting CD19 in B-cell malignancies such as aggressive lymphoma and acute lymphoblastic leukemia. The main toxicities are CRS, immune effector cell-associated neurotoxicity syndrome (ICANS) and cytopenia, which may be prolonged. .1,42 $^{4}$

There has recently been progress in developing CAR T cells to treat MM. ${ }^{43} \mathrm{~T}$ cells are harvested by an unstimulated leukapheresis and genetically modified to generate CAR T cells using a lentiviral or retroviral fusion-construct with an antibody fragment to recognize the tumor antigen and the $T$ cell receptor signaling domain $\mathrm{CD} 3 \zeta$ to activate the modified T-cell (first generation). To further enhance T-cell activation one (second generation) or two (third generation) co-stimulatory domains, usually derived from CD28 or $4-1 \mathrm{BB}$, are added. After in vitro expansion the CAR T cells are re-transfused after lymphodepleting chemotherapy with cyclophosphamide and fludarabine to enhance expansion of the modified $T$ cells.

Several potential targets have been identified on myeloma cells with data for BCMA being the most mature (Table 3). The first-in-human trial was conducted at the National Institutes of Health employing a BCMA-CD28 CAR. Sixteen heavily pretreated patients who received the highest CAR T-cell dose $\left(9 \times 10^{6}\right.$ cells $\left./ \mathrm{kg}\right)$ had an ORR of $81 \%$ including $13 \%$ with complete responses and a median PFS of 7.8 months. CRS grade $3 / 4$ was seen in $38 \%$, ICANS grade $3 / 4$ in $6 \%$ and prolonged cytopenia grade $3 / 4$ in $13 \%$ of the patients. ${ }^{44,45}$

Another phase I trial from the University of Pennsylvania using a BCMA-4-1BB CAR included 25 patients with RRMM. The ORR was $48 \%$ with $8 \%$ having a complete response and a median duration of 
response of 4.2 months. CRS grade $3 / 4$ was seen in $32 \%$ and ICANS grade $3 / 4$ in $12 \%$ of patients. ${ }^{37}$

\section{Idecabtagene vicleucel}

More advanced data have been reported on idecabtagene vicleucel (ide-cel, bb2121) and ciltacabtagene autoleucel. In the phase I study of ide-cel, a BCMA-CD28 construct, 62 RRMM patients were treated with escalating doses from 50 to $800 \times 10^{6}$ cells. The ORR was $76 \%$ with a $39 \%$ complete response rate and a median PFS of 8.8 months with a follow-up of 18.1 months. Toxicity was comparatively low with grade 3/4 CRS occurring in $7 \%$ and ICANS in $2 \%$ of patients. ${ }^{46,47}$

In the phase II KarMMa trial of ide-cel, 128 RRMM patients were treated. The ORR was $73 \%$ with a complete response rate of $33 \%$ and a median PFS of 8.8 months. The rate of grade $3 / 4$ CRS was $5 \%$ and that of ICANS was $3 \%{ }^{48,49}$ In the ongoing KarMMa-2 study idecel is being evaluated in patients who have relapsed early following first-line therapy and in patients who achieved less than a very good partial response after autologous stem cell transplantation. The phase III study, KarMMa-3, is comparing ide-cel with standard-of-care regimens in RRMM.

\section{Ciltacabtagene autoleucel}

Ciltacabtagene autoleucel (cilta-cel, LCAR-B38M or JNJ-4528), a BCMA-4-1BB construct with two BCMA binding domains, was first developed in China. The phase I trial, LEGEND-2, enrolled 57 patients. The ORR was $88 \%$ with $74 \%$ of patients achieving a complete response. The median PFS was 19.9 months. With regard to adverse events, the rate of grade $3 / 4$ CRS was $7 \%$ and no grade $3 / 4$ episodes of ICANS occurred. ${ }^{50-52}$ Cilta-cel was then evaluated in the phase I/II CARTITUDE-1 trial with 97 patients treated so far. The ORR was $97 \%$ and the complete response rate was $67 \%$. At a follow-up of 12.4 months the median PFS had not been reached and the 12 months PFS rate was $76.6 \%$. The rate of grade $3 / 4$ CRS was $5 \%$ while that of grade 3/4 ICANS was only $2 \%$; however, there were also other delayed episodes of neurotoxicity reported in $9 \%$ of the patients in the latest follow-up. ${ }^{53.55}$

In the ongoing CARTITUDE-2 study, cilta-cel is being evaluated following first-line therapy in patients who have not achieved a complete response after autologous stem cell transplantation or in those with prior exposure to a BCMA-targeting drug. Cilta-cel is also being evaluated in the phase III CARTITUDE-4 study comparing CAR $\mathrm{T}$ cells versus pomalidomide-based triplets in lenalidomide-refractory patients.

\section{Allogeneic chimeric antigen receptor $\mathrm{T}$ cells}

The disadvantages of currently available autologous CAR T-cell therapy include the long time needed for production and the reduced fitness of $\mathrm{T}$ cells due to the heavy pretreatment of the patients in current clinical trials. This may be overcome in part by preemptive T-cell collection early during the course of the disease. Off-theshelf allogeneic CAR $T$ cells may be an alternative. Mailankody et al. presented preliminary data on the first allogeneic BCMA CAR T-cell study for RRMM at the ASH meeting in 2020. In these allogeneic CAR T cells the T-cell receptor is knocked out to avoid graft-versus-host disease and CD52 is knocked out to permit the use of an
anti-CD52 antibody for selective and prolonged lymphodepletion to improve engraftment. Gene editing is performed with transcription activator-like effector nuclease (TALEN) technology. The ORR in the group given a dose of $320 \times 10^{6}$ cells was $60 \%$ (6/9 patients) with no grade 3/4 CRS or ICANS or graft-versus-host disease. ${ }^{56}$ CAR-transduced natural killer cord blood cells may be another potential source of future off-the-shelf cellular products. ${ }^{57}$

\section{Discussion}

With the plethora of novel immunotherapy approaches and treatment strategies that are currently in all stages of clinical development, including some recently approved by regulatory authorities, the treatment landscape in $\mathrm{MM}$ is likely to evolve rapidly over the next 5 years, as it did with the introduction of high-dose therapy and autologous blood stem cell transplantation about 30 years ago or with the development of proteasome inhibitors and immunomodulatory drugs in the first decade of this century, followed by monoclonal antibodies in recent years. These novel agents display unprecedented single-agent activity with ORR exceeding $80 \%$ in RRMM patients, translating into response durations of more than 1 year, even in patients with no other treatment options. However, there are, as yet, no phase III clinical datasets available. Therefore, there are still many unanswered questions as to when and how to utilize these different immunotherapeutic agents in our daily clinical practice.

\section{Differences and similarities}

Given the many therapeutic agents that are being developed within each immunotherapeutic class - ADC, TCE, and CAR T cells-much work will be required to assess their relative merits. Most data are available for ADC, for which a range of ocular toxicities have been observed, especially those affecting visual acuity. While belantamab mafodotin induces a clinically significant, reversible keratopathy in about a third of patients, other ADC are associated with lower rates of keratopathy (AMG224) or as yet unexplained photophobia (MEDI2228). However, as the latter two ADC have only been given to limited numbers of patients so far, it is too early to assess potential differences in side effects or even in efficacy.

The same considerations apply to TCE, despite their seemingly similar side-effect profiles, mainly CRS and cytopenias. However, based on early phase clinical trial data, some agents seem to cause CRS less frequently, e.g., TNB-3838, whereas others cause CRS in the majority of patients, yet mostly of minor grade. CC-93269 and talquetamab seem to induce grade 3/4 CRS in some patients. While TNB-3838 was specifically designed to induce less CRS by having a lower affinity for CD3, the reason for the higher CRS rates with other agents remains to be better understood. Of note, the route of administration appears to have an impact on side effects in general and on the rate of CRS specifically, as the rates of both were lower when teclistamab and talquetamab were given subcutaneously rather than intravenously. Interestingly, so far, the specific target of individual TCE does not appear to affect the side-effect profile. Again, it remains to be seen whether these distinctions between 
different agents of the same class will be confirmed in larger trials. However, most patients will favor subcutaneous administration, especially if lower rates of side effects will allow for outpatient use.

Regarding CAR T-cell approaches, the only available data relate to constructs that target BCMA. While phase III results are awaited, the numbers of patients in reported trials are higher and clinical development is more advanced when compared to those for TCE.

For the two most advanced constructs, ide-cel and ciltacel, grade 3/4 CRS and ICANS are relatively uncommon and less of a concern when compared to the side effects of CD19-directed CAR T-cell therapies. Nonetheless, there seem to be differences in the timing of onset of these toxicities. Ide-cel-associated CRS and ICANS emerge within the first 10 and 30 days, respectively, whereas the median times to onset of CRS and ICANS following cilta-cel treatment are 7 and 8 days after infusion, respectively. Moreover, delayed neurotoxicities associated with cilta-cel treatment, not attributable to ICANS, have been reported to occur even several months after infusion. This has implications for the logistics and timing of the required observation period after CAR Tcell therapy.

As it is highly unlikely that we will ever have randomized trials comparing different members of the same class of agents, we will have to wait for larger clinical trials and ultimately real-world post-approval data to tease out the specific characteristics of individual members of the immunotherapeutic armamentarium.

Despite the unprecedented responses to both CAR T cells and TCE, all patients eventually seem to relapse. It is therefore very important to understand mechanisms of resistance to the different immunological therapies, ${ }^{58}$ including lack of CAR T-cell persistence in MM patients, MM cell target antigen loss ${ }^{38}$ and functional inactivation of $\mathrm{T}$ cells by an immunosuppressive microenvironment. ${ }^{59}$ Based on translational data, promising strategies to improve the duration of response to MM immunotherapy include: (i) generation of CAR T cells with a higher potential for persistence in vivo (e.g., by in vitro generation of less exhausted effector-type and more functionally fit naive cells); ;0,61 (ii) targeting more than one MM tumor antigen simultaneously by dual CAR T-cell approaches; ;0,61 and (iii) concurrently inhibiting endogenous tumor escape mechanisms, such as T-cell-expressed immune checkpoint molecules or myeloid cell arginase-mediated arginine deprivation..$^{59}$

\section{Positioning in the treatment landscape}

With increasing treatment options, there needs to be a focus on the timing and sequencing of compounds and strategies. For the time being and likely for the next few years, this issue will be answered (or dictated) by which of these different immunotherapies have been approved for clinical use. However, there is strong interest in using these agents at earlier lines of treatment with less exhausted $\mathrm{T}$ cells present in the bone marrow to be exploited by TCE or available to be transduced into CAR $\mathrm{T}$ cells. In this regard, results from CAR T-cell trials involving less heavily pretreated patients, although still RRMM patients, do not appear to show greater efficacy, notwithstanding all the limitations of inter-trial comparisons and small numbers of patients.

Another important aspect relates to how to use cellular or antibody-based immunotherapy best in hard-to-treat

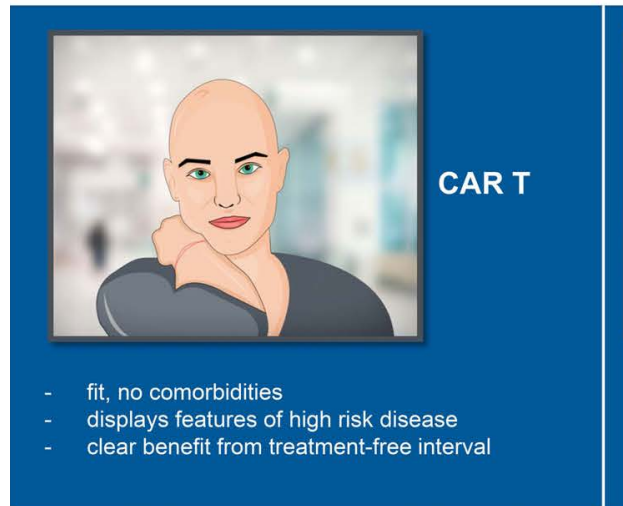

Issues in trials and lacking data

No survival plateau so far

CRS any grade in virtually all patients, CRS ${ }^{\circ}$

CRS any

in $5-10 \%$

Neurotoxicity in up to $20 \%$

Good renal function (GFR $>45 \%$ ) mandatory for

effective lymphodepleting therapy

Some level of MM control necessary before CAR
$\mathrm{T}$ infusion

Limited experience in patients with ECOG $>1$

No experience with CNS involvement

No experience in patients with preexisting CNS

disorders

No experience in patients with $\mathrm{PCL}$

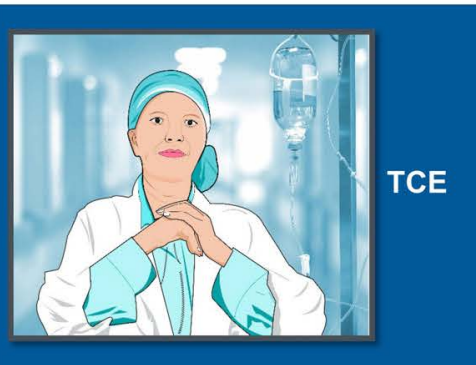

fit, comorbidities acceptable if controlled Standard risk or high risk disease mobility to allow continuous treatment application

Issues in trials and lacking data

CRS any grade in virtually all patients, CRS III in $0-10 \%$

in $0-10 \%$
EMD excluded in some trials

No experience with CNS involvement

No experience in patients with $\mathrm{PCL}$

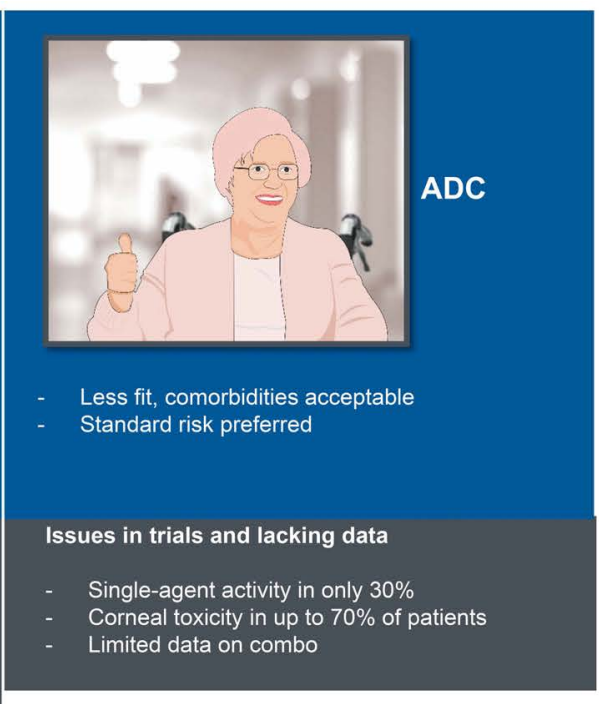

Single-agent activity in only $30 \%$ Cofity in up to $70 \%$ of patients Limited data on combo

Figure 2. Our view on potential patient selection as a basis for further discussion. CAR T: chimeric antigen receptor T cells; TCE: T-cell-engaging antibodies; ADC: antibodydrug conjugate; CRS: cytokine release syndrome; GFR: glomerular filtration rate; MM: multiple myeloma; ECOG: Eastern Cooperative Oncology Group performance status; CNS: central nervous system; PCL: plasma cell leukemia; EMD: extramedullary disease. 
populations of patients, such as those with high-risk MM, early clinical relapse, or extramedullary disease. While reported TCE trials have been too small to allow any conclusion to be drawn, for ide-cel an initial subgroup analysis found that high-risk markers, such as a revised International Staging System score of 3 , even in late-stage refractory disease, are still associated with lower response rates and a shorter median $\mathrm{PFS}{ }^{49}$ For the time being, cellular therapies will be an attractive option for otherwise hard-to-treat, high-risk patients. However, it is possible that cellular immunotherapy might be best used in good-risk patients to induce deep and durable, sustained minimal residual disease negativity in an attempt to cure the disease rather than chasing high-risk disease that is inherently biologically capable of adapting quickly to and thereby prevailing the attack of modified T cells. Preliminary indications can be expected from ongoing studies that address the efficacy of CAR T-cell therapy in patients with early relapse or insufficient response after first-line therapy (e.g., KarMMa-2, CARTITUDE-2) as well as from subgroup analyses of the phase III trials KarMMa-3 and CARTITUDE-4 in relapsed patients after two to four and one to three lines of therapy, respectively.

Other questions regarding the best use of cellular or antibody-based immunotherapies include their place relative to autologous stem cell transplantation, their role in post-transplant consolidation, in the treatment of persistent minimal residual disease positivity, and their potential to replace or shorten maintenance therapy. One fundamental difference between these two immune-based approaches is how quickly they can be provided to a given patient. CAR T cells need to be manufactured, requiring several weeks of planning, scheduling, and possibly bridging treatment, at least with current technology and constructs. This setting appears to be best integrated into an established treatment algorithm, similar to that for autologous stem cell transplantation, or in a setting of consolidation or minimal residual disease. TCE, conversely, are readily available and represent an outpatient community-based option, although uncertainties relating to repeated dosing and treatment-free intervals need to be explored. However, TCE are suitable candidates for integration into combination regimens, a strategy that has previously been proven to result in superior outcomes for patients.

\section{Selecting the right patient}

Last but not least, the most frequently asked question relates to patient selection. As the first $\mathrm{ADC}$ was approved in Europe and the USA in 2020, and as the first CAR T-cell construct is expected to be approved early in 2021, this is a clinically pressing concern (Figure 2).

Cellular immunotherapy should not be limited to certain age groups, but should rather be considered for use in fit patients, without significant comorbidities, who would tolerate intensive care treatment if CRS or ICANS occurs. Patients would need to be able to travel to the designated cell-therapy centers and close collaboration between these centers and community-based hematologists is required.

T-cell engagers, such as TCE or modified $\mathrm{BiTE}^{\circledR}$, are associated with a lower risk of immune-mediated toxicities such as high-grade CRS or ICANS, as a result of which less-fit patients can be considered as treatment candidates. In addition, patients with high disease dynamics requiring urgent treatment might benefit from the immediate availability of TCE.

Finally, ADC may be potentially suitable for frail patients if the patients are closely monitored for keratopathy or other ophthalmological side effects. However, these toxicities may impact and limit activities of daily life. The relatively long intervals of 3 weeks between therapy administration may more easily allow for treatment of patients with limited mobility. (Figure 2)

Despite all remaining open questions and issues that still need to be addressed, and hopefully answered and resolved within the next years, we are now, without any doubt, at the dawn of a new era that will significantly improve patients' outcome. There is a light at the horizon towards curing MM.

\section{Disclosures}

$L R$ has received a grant from Skyline $D x$ and personal fees from BMS, Janssen, GSK, Sanofi and Oncopeptides. RW has received grants from Janssen and Sanofi and personal fees from Janssen, Novartis, BMS/Celgene, Amgen, Gilead, Pfizer, Sanofi and Takeda. $M M$ has received a grant from Incyte, personal fees from Janssen, Amgen, BMS, Abbvie, Sanofi, GSK and Takeda, and non-financial support from Janssen, Amgen and BMS. HG has received grants from: Amgen, BMS, Celgene, Chugai, Janssen, Sanofi and Takeda, personal fees from: Amgen, BMS, Celgene, Chugai, Janssen, Sanofi, Takeda, Novartis, Adaptive Biotechnologies and Glaxo Smith Kline (GSK), non-financial-support from Amgen, BMS, Celgene, Janssen, Sanofi and Takeda, and research support from Amgen, BMS, Celgene, Chugai, Janssen, Sanofi, Incyte, Molecular Partners, Merck Sharp and Dohme (MSD), Mundipharma, Takeda and Novartis. MSR has received grants from BMS, Novartis, Amgen and Sanofi, and personal fees from BMS, Novartis, Amgen, Janssen and Sanofi.

\section{Contributions}

$L R$ and MSR wrote the manuscript, RW and MM contributed topic-specific sections. All authors read, revised, and approved the submitted manuscript.

\section{Acknowledgments}

The authors thank Patrick J. Hayden for helpful discussions and excellent native-speaker language editing of the manuscript.

\section{References}

1. Gogishvili T, Danhof S, Prommersberger S, et al. SLAMF7-CAR T cells eliminate myelo$\mathrm{ma}$ and confer selective fratricide of SLAMF7(+) normal lymphocytes. Blood. 2017;130(26):2838-2847.

2. Nijhof IS, Groen RW, Lokhorst HM, et al. Upregulation of CD38 expression on multi- ple myeloma cells by all-trans retinoic acid improves the efficacy of daratumumab. Leukemia. 2015;29(10):2039-2049.

3. Garcia-Guerrero E, Gotz R, Doose S, et al. Upregulation of CD38 expression on multiple myeloma cells by novel HDAC6 inhibitors is a class effect and augments the efficacy of daratumumab. Leukemia. 2020;35(1):201-214

4. Ogiya D, Liu J, Ohguchi H, et al. The JAK-
STAT pathway regulates CD38 on myeloma cells in the bone marrow microenvironment: therapeutic implications. Blood. 2020;136(20):2334-2345.

5. Nerreter T, Letschert S, Gotz R, et al. Superresolution microscopy reveals ultra-low CD19 expression on myeloma cells that triggers elimination by CD19 CAR-T. Nat Commun. 2019;10(1):3137.

6. Smith EL, Harrington K, Staehr M, et al 
GPRC5D is a target for the immunotherapy of multiple myeloma with rationally designed CAR T cells. Sci Transl Med. 2019;11(485):eaau7746.

7. Li J, Stagg NJ, Johnston J, et al. Membraneproximal epitope facilitates efficient $T$ cell synapse formation by anti-FcRH5/CD3 and is a requirement for myeloma cell killing. Cancer Cell. 2017;31(3):383-395.

8. Bruins WSC, Zweegman S, Mutis T, van de Donk N. Targeted therapy with immunoconjugates for multiple myeloma. Front Immunol. 2020;11:1155

9. Demel I, Bago JR, Hajek R, Jelinek T. Focus on monoclonal antibodies targeting B-cell maturation antigen (BCMA) in multiple myeloma: update 2020. Br J Haematol. 2021;193(4):705-722.

10. Shah N, Chari A, Scott E, Mezzi K, Usmani SZ. B-cell maturation antigen (BCMA) in multiple myeloma: rationale for targeting and current therapeutic approaches. Leukemia. 2020;34(4):985-1005.

11. Lonial S, Lee HC, Badros A, et al. Belantamab mafodotin for relapsed or refractory multiple myeloma (DREAMM-2): a two-arm, randomised, open-label, phase 2 study. Lancet Oncol. 2020;21(2):207-221.

12. Farooq AV, Degli Esposti S, Popat R, et al. Corneal epithelial findings in patients with multiple myeloma treated with antibodydrug conjugate belantamab mafodotin in the pivotal, randomized, DREAMM-2 study. Ophthalmol Ther. 2020;9(4):889-911.

13. Nooka AK MM, Bahlis N, Weisel K, et al. DREAMM-4: evaluating safety and clinical activity of belantamab mafodotin in combination with pembrolizumab in patients with relapsed/refractory multiple myeloma (RRMM). Hematol Rep. 2020;12(s1):EP955.

14. Popat R, Stockerl-Goldstein K, Abonour R, et al. DREAMM-6: safety, tolerability and clinical activity of belantamab mafodotin (Belamaf) in combination with bortezomib/dexamethasone (BorDex) in relapsed/refractory multiple myeloma (RRMM). Blood. 2020;136(Suppl 1):1419.

15. Trudel S, McCurdy A, Sutherland HJ, et al. Part 1. Results of a dose finding study of belantamab mafodotin (GSK2857916) in combination with pomalidomide (POM) and dexamethasone (DEX) for the treatment of relapsed/refractory multiple myeloma (RRMM). Blood. 2020;136(Suppl 1):725

16. Lancman G, Richter J, Chari A. Bispecifics, trispecifics, and other novel immune treatments in myeloma. Hematology Am Soc Hematol Educ Program. 2020;2020(1):264271

17. Xing L, Lin L, Yu T, et al. A novel BCMA PBD-ADC with ATM/ATR/WEE1 inhibitors or bortezomib induce synergistic lethality in multiple myeloma. Leukemia. 2020;34(8): 2150-2162.

18. Kumar SK, Migkou M, Bhutani M, et al. Phase 1, first-in-human study of MEDI2228, a BCMA-targeted ADC in patients with relapsed/refractory multiple myeloma. Blood 2020;136 (Suppl 1):179.

19. Trudel S, Lendvai N, Popat $R$, et al. Antibody-drug conjugate, GSK2857916, in relapsed/refractory multiple myeloma: an update on safety and efficacy from dose expansion phase I study bispecifics, trispecifics, and other novel immune treatments in myeloma. Focus on monoclonal antibodies targeting B-cell maturation antigen (BCMA) in multiple myeloma: update 2020. Blood Cancer J. 2019:9(4):37.

20. Lee HC, Raje NS, Landgren O, et al. Phase 1 study of the anti-BCMA antibody-drug con- jugate AMG 224 in patients with relapsed/refractory multiple myeloma. Leukemia. 2020;35(1):255-258

21. Bruins WSC, Zheng W, Higgins JP, et al TAK-169, a novel recombinant immunotoxin specific for $\mathrm{CD} 38$, induces powerful preclinical activity against patient-derived multiple myeloma cells. Blood. 2020;136(Suppl 1):1363.

22. Vogl DT, Kaufman JL, Holstein SA, et al. TAK-573, an anti-CD38/attenuated Ifno fusion protein, has clinical activity and modulates the Ifno receptor (IFNAR) pathway in patients with relapsed/refractory multiple myeloma. Blood. 2020;136(Suppl 1):3197.

23. Sherbenou DW, Aftab BT, Su Y, et al Antibody-drug conjugate targeting CD46 eliminates multiple myeloma cells. J Clin Invest. 2016;126(12):4640-4653.

24. Pahl A, Lutz C, Hechler T. Amanitins and their development as a payload for antibody-drug conjugates. Drug Discov Today Technol. 2018;30:85-89.

25. Figueroa-Vazquez V, Ko J, Breunig C, et al HDP-101, anti-BCMA antibody-drug conjugate, safely delivers amanitin to induce cell death in proliferating and resting multiple myeloma cells. Mol Cancer Ther. 2020;20 (2):367-378

26. Strassz A, Raab MS, Orlowski RZ, et al. A first in human study planned to evaluate Hdp-101, an anti-BCMA amanitin antibodydrug conjugate with a new payload and a new mode of action, in multiple myeloma. Blood. 2020;136(Suppl 1):3230

27. Topp MS, Duell J, Zugmaier G, et al. Evaluation of AMG 420, an anti-BCMA bispecific T-cell engager (BiTE) immunotherapy, in R/R multiple myeloma (MM) patients: updated results of a first-in-human (FIH) phase I dose escalation study. J Clin Oncol. 2019;37(15_suppl):8007.

28. Topp MS, Mauser M, Einsele H. Outcome of BCMA Bite (AMG420) therapy in relapse and refractory multiple myeloma (RRMM) patients. Blood. 2020;136(Suppl 1):3223

29. Garfall AL, Usmani SZ, Mateos MV, et al. Updated phase 1 results of teclistamab, a Bcell maturation antigen (BCMA) x CD3 bispecific antibody, in relapsed and/or refractory multiple myeloma (RRMM). Blood. 2020:136(Suppl 1):180.

30. Madduri D, Rosko A, Brayer J, et al REGN5458, a BCMA x CD3 bispecific monoclonal antibody, induces deep and durable responses in patients with relapsed/refractory multiple myeloma (RRMM). Blood. 2020;136(Suppl 1):291.

31. Buelow B, D'Souza A, Rodriguez C, et al. TNB383B.0001: a multicenter, phase 1, open-label, dose-escalation and expansion study of TNB-383B, a bispecific antibody targeting BCMA in subjects with relapsed or refractory multiple myeloma. Blood. 2019;134(Suppl_1):1874.

32. Rodriguez C, D'Souza A, Shah N, et al Initial results of a phase I study of TNB383B, a BCMA x CD3 bispecific T-cell redirecting antibody, in relapsed/refractory multiple myeloma. Blood. 2020;136(Suppl 1):293

33. Harrison SJ, Minnema MC, Lee HC, et al. A phase 1 first in human (FIH) study of AMG 701, an anti-B-cell maturation antigen (BCMA) half-life extended (HLE) BiTE® (bispecific T-cell engager) molecule, in relapsed/refractory (RR) multiple myeloma (MM). Blood. 2020;136(Suppl 1):181.

34. Lesokhin AM, Levy MY, Dalovisio AP, et al. Preliminary safety, efficacy, pharmacokinetics, and pharmacodynamics of subcuta- neously (SC) administered PF-06863135, a $\mathrm{B}$-cell maturation antigen (BCMA)-CD3 bispecific antibody, in patients with relapsed/refractory multiple myeloma (RRMM). Blood. 2020;136(Suppl 1):3206.

35. Seckinger A, Delgado JA, Moser S, et al Target expression, generation, preclinical activity, and pharmacokinetics of the BCMA-T cell bispecific antibody EM801 for multiple myeloma treatment. Cancer Cell. 2017;31(3):396-410

36. Costa LJ, Wong SW, Bermudez A, et al. First clinical study of the B-cell maturation antigen (BCMA) 2+1 T cell engager (TCE) CC 93269 in patients (Pts) with relapsed/refractory multiple myeloma (RRMM): interim results of a phase 1 multicenter trial. Blood. 2019;134(Supplement 1):143.

37. Cohen AD, Garfall AL, Stadtmauer EA, et al. $B$ cell maturation antigen-specific CAR T cells are clinically active in multiple myeloma. J Clin Invest. 2019;129(6):2210-2221.

38. Da Via MC, Dietrich O, Truger M, et al. Homozygous BCMA gene deletion in response to anti-BCMA CAR $T$ cells in a patient with multiple myeloma. Nat Med. 2021;27(4):616-619.

39. Chari A, Berdeja JG, Oriol A, et al. A phase 1, first-in-human study of talquetamab, a $G$ protein-coupled receptor family $\mathrm{C}$ group 5 member D (GPRC5D) x CD3 bispecific antibody, in patients with relapsed and/or refractory multiple myeloma (RRMM). Blood. 2020;136(Suppl 1):290

40. Cohen AD, Harrison SJ, Krishan A, et al. Initial clinical activity and safety of BFCR4350A, a FcRH5/CD3 T-cell-engaging bispecific antibody, in relapsed/refractory multiple myeloma. Blood. 2020;136(Suppl 1):292.

41. Lee DW, Santomasso BD, Locke FL, et al. ASTCT consensus grading for cytokine release syndrome and neurologic toxicity associated with immune effector cells. Bio Blood Marrow Transplant. 2019;25(4):625638.

42. Wäsch R, Munder M, Marks R. Teaming up for CAR-T cell therapy. Haematologica. 2019:104(12):2335-2336

43. Köhler M, Greil C, Hudecek M, et al Current developments in immunotherapy in the treatment of multiple myeloma. Cancer 2018;124(10):2075-2085.

44. Ali SA, Shi V, Maric I, et al. T cells expressing an anti-B-cell maturation antigen chimeric antigen receptor cause remissions of multiple myeloma. Blood. 2016;128(13):1688-1700.

45. Brudno JN, Maric I, Hartman SD, et al. T cells genetically modified to express an antiB-cell maturation antigen chimeric antigen receptor cause remissions of poor-prognosis relapsed multiple myeloma. J Clin Oncol. 2018;36(22):2267-2280.

46. Raje N, Berdeja J, Lin Y, et al. Anti-BCMA CAR T-cell therapy bb2121 in relapsed or refractory multiple myeloma. $\mathrm{N}$ Engl J Med. 2019:380(18):1726-1737.

47. Lin Y RN, Raje NS, Berdeja JG, et al Idecabtagene vicleucel (ide-cel, bb2121), a BCMA-directed CAR T cell therapy, in patients with relapsed and refractory multiple myeloma: updated results from phase 1 CRB-401 study. Blood. 2020;136(Suppl 1):131.

48. Munshi NC, Anderson LD, Shah N, et al. Idecabtagene vicleucel (ide-cel; bb2121), a BCMA-targeted CAR T-cell therapy, in patients with relapsed and refractory multiple myeloma (RRMM):initial KarMMa results. J Clin Oncol. 2020;38(15-suppl): 8503 . 
49. Raje NS, Siegel DS, Jagannath S, et al. Idecabtagene vicleucel (ide-cel, bb2121) in relapsed and refractory multiple myeloma: analyses of high-risk subgroups in the KarMMa study. Blood. 2020;136(Suppl 1):37-38.

50. Zhao J, Lin Q, Song Y, Liu D. Universal CAR, universal $T$ cells, and universal CAR T cells. J Hematol Oncol. 2018;11(1):132.

51. Xu J, Chen LJ, Yang SS, et al. Exploratory trial of a biepitopic CAR T-targeting B cell maturation antigen in relapsed/refractory multiple myeloma. Proc Natl Acad Sci U S A. 2019;116(19):9543-9551.

52. Wang BY, Zhao WH, Liu J, et al. Long-term follow-up of a phase 1, first-in-human openlabel study of LCAR-B38M, a structurally differentiated chimeric antigen receptor $\mathrm{T}$ (CAR-T) cell therapy targeting B-cell maturation antigen (BCMA), in patients (pts) with relapsed/refractory multiple myeloma (RRMM). Blood. 2019;134(Suppl 1):579.
53. Madduri D, Usmani SZ, Jagannath $S$, et al Results from CARTITUDE-1: a phase 1b/2 study of JNJ-4528, a CAR-T cell therapy directed against B-cell maturation antigen (BCMA), in patients with relapsed and/or refractory multiple myeloma (R/R MM). Blood. 2019;134(Suppl 1):577.

54. Berdeja J, Madduri D, Usmani SZ, et al Update of CARTITUDE-1: a phase Ib/I study of JNJ-4528, a B-cell maturation antigen (BCMA)-directed CAR-T-cell therapy, in relapsed/refractory multiple myeloma. J Clin Oncol. 2020;38(15-Suppl):8505.

55. Madduri D, Berdeja JG, Usmani SZ, et al. CARTITUDE-1: phase $1 \mathrm{~b} / 2$ study of ciltacabtagene autoleucel, a B-cell maturation antigen-directed chimeric antigen receptor $\mathrm{T}$ cell therapy, in relapsed/refractory multiple myeloma. Blood. 2020;136(Suppl 1):22-25.

56. Mailankody S, Matous JV, Liedtke M, et al. Universal: an allogeneic first-in-human study of the anti-BCMA ALLO-715 and the
anti-CD52 ALLO-647 in relapsed/refractory multiple myeloma. Blood. 2020;136(Supp 1):24-25.

57. Liu E, Marin D, Banerjee P, et al. Use of CAR-transduced natural killer cells in CD19positive lymphoid tumors. N Engl J Med. 2020;382(6):545-553

58. D'Agostino M, Raje N. Anti-BCMA CAR Tcell therapy in multiple myeloma: can we do better? Leukemia. 2020;34(1):21-34

59. Leone P, Solimando AG, Malerba E, et al. Actors on the scene: immune cells in the myeloma niche. Front Oncol. 2020;10 599098.

60. Wudhikarn K, Mailankody S, Smith EL Future of CAR T cells in multiple myeloma. Hematology Am Soc Hematol Educ Program. 2020;2020(1):272-279.

61. Shah UA, Mailankody S. CAR T and CAR NK cells in multiple myeloma: expanding the targets. Best Pract Res Clin Haematol. 2020;33(1):101141. 